\title{
Failure of Ploidy and Proliferative Fraction to Predict Long- Term Outcome After Prostatectomy
}

\author{
Gregory P. Swanson ${ }^{\mathrm{a}, \mathrm{d}}$, Wencong Chen ${ }^{\mathrm{b}}$, V.O. Speights ${ }^{\mathrm{c}}$
}

\begin{abstract}
Background: Historically, ploidy and S phase percentage appeared to be promising predictors for prostate cancer recurrence. Lack of uniformity and consistency hampered their development. We evaluated ploidy and $\mathrm{S}$ phase for prostate cancer death in a cohort of patients with long-term follow-up.
\end{abstract}

Methods: We identified 127 patients that had ploidy and S phase determined at the time of their radical prostatectomy for prostate cancer. With 15 years of follow-up, we determined the risk of biochemical failure and risk of death from prostate cancer. We correlated the S phase and ploidy findings with standard pathology findings.

Results: A total of 107 (84\%) had diploid and 20 (16\%) had non-diploid cancers. The median S phase was $6.6 \%$. There was no correlation of ploidy $(\mathrm{P}=0.472)$ or $\mathrm{S}$ phase with preoperative PSA or Gleason score. On univariate analysis, EPE, margin positivity, seminal vesicle involvement, lymph node involvement, high Gleason score and PSA > $10 \mathrm{ng} / \mathrm{mL}$ were all predictive of biochemical failure. Ploidy and S phase were not. For prostate cancer death, only Gleason score was predictive.

Conclusions: With long-term follow-up in our cohort, Gleason score was predictive of prostate cancer death. Ploidy and S phase were not predictive for biochemical failure or prostate cancer mortality.

Keywords: Ploidy; Diploid; Anueploid; S phase

\section{Introduction}

There is long standing interest in prognostic determinants for

Manuscript submitted April 24, 2018, accepted May 15, 2018

aDepartment of Radiation Oncology, Baylor Scott \& White Healthcare, Temple TX, USA

${ }^{b}$ Department of Biostatistics, Baylor Scott \& White Research Institute, Temple, TX, USA

'Department of Pathology, Baylor Scott \& White Healthcare, Temple, TX, USA

${ }^{\mathrm{d}}$ Corresponding Author: Gregory P. Swanson, Baylor Scott \& White Healthcare, 2401 S. 31st Street, Temple, TX 76508, USA.

Email:Gregory.swanson@BSWhealth.org

doi: https://doi.org/10.14740/wjon1111w cancer outside standard pathology. The earliest attempts focused on chromosomal abnormalities and evaluation of the proliferative state of the cancer cells. By the 1980's this evolved into more systematic evaluations regarding ploidy and $\mathrm{S}$ phase (proliferative faction), enabled by high-throughput flow cytometry. Initially, the greatest utility was in breast cancer where results were used to assess the need for cytotoxic therapy $[1,2]$. Although ploidy and S phase were investigated in prostate cancer, it was never clear as to whether they added any prognostic information. Although some large studies were done, they were hampered by disparate groups of patients with follow-up too short to determine whether they were predictive of survival.

We had previously evaluated a large cohort of patients for risk of failure after radical prostatectomy and found that pathologic stage, Gleason score, and pre-treatment PSA all influenced the risk of recurrence [3]. A subgroup of those patients also had ploidy and S-phase determined and we now have the opportunity to determine whether those findings and any additional prognostic information for cancer recurrence and survival on long-term follow-up.

\section{Materials and Methods}

With approval of the local institutional review board (IRB), we performed a search of the pathology records from 1987 - 1995 for radical prostatectomy patients that had flow cytometry for $\mathrm{S}$ phase and ploidy performed at the time of surgery. There was no predetermined criterion at the time, flow cytometry was being routinely performed in breast cancer patients and it was thought it might also be helpful in prostate cancer patients. We were able to identify 127 patients. Patient characteristics are shown in Table 1. The pathological findings of extracapsular extension, seminal vesicle involvement, margin involvement, lymph node involvement and Gleason score were recorded. Gleason grade and score was reviewed and updated as per contemporary guidelines [4]. We determined the follow-up of all the patients through October 2017.

Flow cytometry for ploidy and $\mathrm{S}$ phase of the cancer was performed at the time of prostatectomy pathological evaluation after the tissue was paraffin embedded. The tissue was sectioned with portions containing cancer deparaffinized and then digested in a pepsin solution to separate the cells producing a single cell suspension. They were then prepared using proteinase K and then treated with RNAse. The cells that were stained with propidium iodide were then analyzed on the flow cytometer (fluorescence activated cell sorter, Becton Dickinson, Sun- 
Table 1. Patient Characteristics

\begin{tabular}{|c|c|c|c|c|}
\hline & Number & Mean & Med & Range \\
\hline Age at surgery & 127 & 66 yrs & $67 \mathrm{yrs}$ & $47-83$ \\
\hline Preoperative PSA & 121 & $10.4 \mathrm{ng} / \mathrm{mL}$ & $10.3 \mathrm{ng} / \mathrm{mL}$ & $1.4-54.6$ \\
\hline \multicolumn{5}{|l|}{ Gleason } \\
\hline$<7$ & 59 & & & \\
\hline$>7$ & 9 & & & \\
\hline \multicolumn{5}{|l|}{ Ploidy } \\
\hline Diploid & 107 & & & \\
\hline Aneuploid & 20 & & & \\
\hline \multicolumn{5}{|l|}{ Pathology findings } \\
\hline Mar+ & 30 & & & \\
\hline
\end{tabular}

LN: lymph nodes; SV: seminal vesicles; EPE: extraprostatic extension; Mar: margins.

nyvale, California) which utilized a $5 \mathrm{~W}$ argon laser at a $514 \mathrm{~nm}$ wavelength. Histograms of 10,000 nuclei were recorded and evaluated for cell cycle. The three largest peaks were recorded; the diploid G0/G1 peak (DNA index of $1.00-1.10$ ), the tetraploid G2 (DNA index 1.9 - 2.1) peak and the third peak designated as aneuploidy (DNA index $<1.00$ or $>1.10$ ). Since there were only two tetraploid tumors, those patients were combined with the aneuploid patients. The $\mathrm{S}$ phase analysis was calculated using the CEllFIT program of the scanner for the diploid tumors. In analysis, the median $\mathrm{S}$ phase for our patients was used as no significant level could be identified.

\section{Statistical methods}

The trend of proportion of ploidy status and $\mathrm{S}$ phase across Gleason score was analyzed by Mantel-Haenszel Chi-square test. For the association of ploidy status and S phase with PSA was analyzed by Chi-Square test. If there is at least one cell that expected count less than 5, Fisher's exact test will be performed. For the relationship of each prognostic factor, MantelHaenszel Chi-square test and Chi-square test were used to test the association. If there is at least one cell that expected count less than 5, Fisher's exact test was performed. P values less than 0.05 were considered to indicate statistical significance.

Time to death caused by prostate cancer was analyzed by a Cox proportional hazards model, adjusted by baseline PSA value, total Gleason score, EPE, lymph nodes, margin, diploid, S phase, and SV. Only total Gleason score was statistical significant; $\mathrm{P}=0.0023$ at full model and $\mathrm{P}=0.0003$ after a forward model selection. The model based hazards ratio were determined for Gleason $=7$ vs. Gleason $<7$ and Gleason $>7$ vs. Gleason $<7$. The assumption of Cox proportional hazard model was checked by graphical output and resample procedure.

\section{Results}

Mean follow-up was 13.0 years (median 12.3 years) overall and 15.1 years (median 13.1 years) for survivors. The median age of the patients was 67 years at the time of surgery. Median preoperative PSA was $10.4 \mathrm{ng} / \mathrm{mL}$ and 107 (84\%) had diploid and $20(16 \%)$ had non-diploid (aneuploid) cancers. The mean and median $\mathrm{S}$ phase in the diploid tumors was $8.2 \%$ and $6.6 \%$ respectively (Table 1 ).

There was no correlation of ploidy $(\mathrm{P}=0.472)$ or $\mathrm{S}$ phase less than or greater than the median $(6.6 \%)(\mathrm{P}=0.682)$ with preoperative PSA (less or greater than $10 \mathrm{ng} / \mathrm{mL}$ ). There was also no association of ploidy $(\mathrm{P}=0.348)$ or $\mathrm{S}$ phase $(\mathrm{P}=0.483)$ with Gleason score (<7 vs. 7 vs. $>7$ ) (Table 2$)$.

On univariate analysis, we evaluated each distinct pathological factor for outcome on biochemical failure and prostate cancer death (Table 3). The presence of extraprostatic extension (EPE), margin positivity, seminal vesicle involvement, lymph node involvement, high Gleason score and PSA $>10$ $\mathrm{ng} / \mathrm{mL}$ were all predictive of biochemical failure. Ploidy and $\mathrm{S}$ phase were not. On multivariate analysis, EPE $(\mathrm{P}=0.004)$, Gleason score $(\mathrm{P}=0.0365)$ and PSA $(\mathrm{P}=0.0012)$ remained significant. For prostate cancer death, only Gleason score was predictive $(\mathrm{P}=0.0023)$ on univariate and multivariate analysis (Table 3).

\section{Discussion}

In the last 20 years, the pathologic risk factors for recurrence after prostatectomy are fairly well established, consisting of Gleason score, PSA level, extraprostatic extension, seminal vesicle involvement, lymph node metastases and positive mar- 
Table 2. Association of Ploidy and S Phase With Gleason Score and PSA

\begin{tabular}{|c|c|c|c|c|c|c|c|}
\hline & Gleason $<7(\%)$ & Gleason $7(\%)$ & Gleason > $7(\%)$ & P value & PSA $<10(\%)$ & PSA $>10(\%)$ & P value \\
\hline Diploid & $51(48 \%)$ & $47(44 \%)$ & $9(8 \%)$ & $0.348^{\mathbb{1}}$ & $78(73 \%)$ & $29(27 \%)$ & $0.472^{£}$ \\
\hline Non-diploid & $8(40 \%)$ & $12(60 \%)$ & 0 & & $13(65 \%)$ & $7(35 \%)$ & \\
\hline S phase $>6.6 \%$ & $22(42 \%)$ & $28(53 \%)$ & $3(6 \%)$ & & $39(74 \%)$ & $14(26 \%)$ & \\
\hline
\end{tabular}

IP-value was calculated by Mantel-Haenszel Chi-square test. ${ }^{£} \mathrm{P}$-value was calculated by Fisher' exact Chi-square test. ${ }^{ \pm} \mathrm{P}$-value was calculated by Pearson Chi-square test.

gins [5]. These factors have been evaluated and confirmed in nomograms with a 0.79 concordance across groups [6].

In our current analysis, PSA, Gleason score and EPE remained predictive of failure, but only Gleason score was prognostic for prostate cancer death. Percent S phase and ploidy were not predictive of failure or death. Our hope that $\mathrm{S}$ phase and ploidy would add additional prognostic information was unrealized.

The interest in ploidy analysis stems from the obvious departure from normal for non-diploid cells. The idea is that this apparent genetic instability could be mechanistic in the malignant state. Indeed, in risk assessment, it is widely observed that aneuploidy predicts for a worse prognosis. This has been studied most extensively in breast cancer $[1,2]$. In prostate cancer, the reported distribution of chromosome number is fairly broad, usually ranging from $63-83 \%$ diploid [7-10]. It has been reported as low as $43 \%$ and $50 \%[11,12]$.
Our findings (84\%) were at the higher end. When reported separately (it is usually classified as aneuploid), tetraploidy usually occurs less than $10 \%$ of the time, but some studies report an incidence of $10-20 \%[8,10,11,13]$. The wide range of findings is likely a reflection of different patient populations and techniques. Some studies were done with core needle biopsies and some with tissue from prostatectomy. It is this very lack of uniformity and consistency which has hampered the widespread adoption of ploidy as a prognostic factor $[1,2]$.

Specific to our patients, a recent review [14] cited numerous studies with varying risk factors showing aneuploid tumors had a worse outcome after radical prostatectomy than diploid tumors, although is not confirmed by everyone [12]. Most of those studies were evaluating patients with the addition of androgen ablation or radiation. In the largest reported prostatectomy study [10], aneuploid cancers had a $24 \%$ dec-

Table 3. Biochemical Failure Based on Each Factor

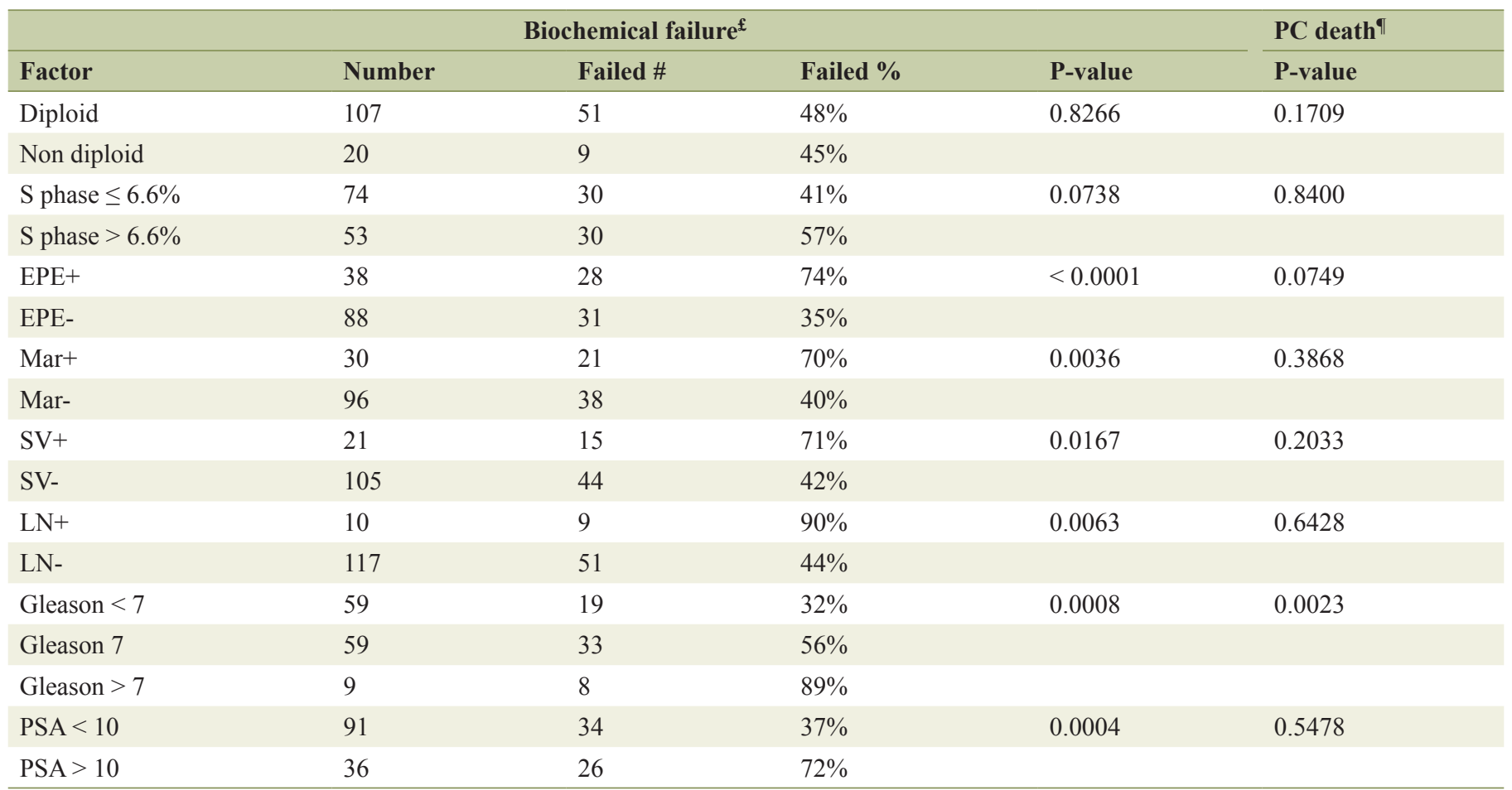

EP-values were calculated by Pearson Chi-square test or Mantel-Haenszel Chi-square test. When at least one cell that expected count less than 5 , Fisher's exact test was implemented. IPC death is the death caused by prostate cancer. P values were calculated with the use of Cox proportionalhazards models. 
rement in 5-year PSA failure free survival in patients with pathological organ confined disease. In the other large prostatectomy study of patients from the same institution that only had pT3 disease [15], 49\% were non-diploid and had a higher risk of recurrence, but effect on survival was not reported. In our series, which was not limited to specific pathological subgroups, aneuploidy occurred $16 \%$ of the time, but was not predictive for biochemical failure or prostate cancer specific survival. It may be that the best use of ploidy is in patients from specifically defined pathologic subgroups. We did not have enough patients to look at that specifically, but in multivariate analysis, the pathologic features remained a stronger predictor of failure.

In addition to ploidy, it has been long considered that one of the hall marks of cancer is a high proliferative rate. $\mathrm{S}$ phase is thought to be indicative of the proliferative rate as that is where active DNA replication is ongoing in preparation for mitosis. With the development of flow cytometry, large number of cells can be analyzed. In cells with an abnormal chromosome number (aneuploid), multiple cell populations (and hence $\mathrm{S}$ phases) are present which complicates $\mathrm{S}$ phase determination [16]. Given that those cells already have the negative connotation of being morphologically abnormal, we measured S only in the diploid cells. The use of S phase has been widely studied in breast cancer and has clear prognostic implications. Although often associated with higher grade cancer, on multivariate analysis, high $\mathrm{S}$ phase (generally considered at $>6 \%$ ) has been found to be a marker for decreased disease free and overall survival. As with the determination of ploidy, the widespread adoption of S phase is hampered by the lack of uniformity in testing so that results are not readily comparable across institutions $[1,2]$. In prostate cancer, there are relatively few studies reporting on the influence of $\mathrm{S}$ phase on outcome. In one of the larger series (322 patients) of patients after radical prostatectomy, the mean and median $\mathrm{S}$ phase were relatively low at $3.1 \%$ and $2.0 \%$, respectively [13]. Higher Gleason scores were associated with higher S phase, which has been reported by others, but not in our series. They didn't report outcomes and there is a paucity of studies of prostatectomy patients looking at the influence of $\mathrm{S}$ phase on outcome. In one study of 55 patients [17], S phase over $14 \%$ was predictive for biochemical failure (> $>0 \%$ vs. 0 for $<14 \%$ ). We didn't see that difference, perhaps because our cohort was larger and included a wider range of patients with other competing risk factors. It may well be that the best utility of S phase may be in patients with lower risk with conventional parameters.

As noted, there are fairly well established prognostic factors for failure after prostatectomy for prostate cancer [5]. There is great interest in improving the specificity and early on, ploidy and S phase looked promising. The lack of consistency in patient selection and techniques has hampered further development. This is true with a large number of promising potential prognostic markers [18]. Without an established pathway for developing and confirming the benefit of new markers, we will be left to industry to so. This has occurred with the development of the Prolaris ${ }^{\circledR}$, Oncotype DX ${ }^{\circledR}$ and Decipher $\AA$ molecular panels. For now, ploidy and $\mathrm{S}$ phase will become a historical footnote.

\section{References}

1. Wenger CR, Clark GM. S-phase fraction and breast cancer - a decade of experience. Breast Cancer Res Treat. 1998;51(3):255-265.

2. Harris L, Fritsche H, Mennel R, Norton L, Ravdin P, Taube S, Somerfield MR, et al. American Society of Clinical Oncology 2007 update of recommendations for the use of tumor markers in breast cancer. J Clin Oncol. 2007;25(33):5287-5312.

3. Swanson GP, Riggs M, Hermans M. Pathologic findings at radical prostatectomy: risk factors for failure and death. Urol Oncol. 2007;25(2):110-114.

4. Epstein JI, Allsbrook WC, Jr., Amin MB, Egevad LL, Committee IG. The 2005 International Society of Urological Pathology (ISUP) Consensus Conference on gleason grading of prostatic carcinoma. Am J Surg Pathol. 2005;29(9):1228-1242.

5. Swanson GP, Basler JW. Prognostic factors for failure after prostatectomy. J Cancer. 2010;2:1-19.

6. Swanson GP, Yu C, Kattan MW, Hermans MR. Validation of postoperative nomograms in prostate cancer patients with long-term follow-up. Urology. 2011;78(1):105-109.

7. Shockley KF, Maatman TJ, Carothers GC, Warzynski MJ. Comparative analysis of prognostic factors in men undergoing radical prostatectomy for adenocarcinoma of the prostate, including DNA ploidy, surgical tumor stage, prostatic specific antigen, Gleason grade, and age. Prostate. 1996;29(1):46-50.

8. Sebo TJ, Cheville JC, Riehle DL, Lohse CM, Pankratz VS, Myers RP, Blute ML, et al. Predicting prostate carcinoma volume and stage at radical prostatectomy by assessing needle biopsy specimens for percent surface area and cores positive for carcinoma, perineural invasion, Gleason score, DNA ploidy and proliferation, and preoperative serum prostate specific antigen: a report of 454 cases. Cancer. 2001;91(11):2196-2204.

9. Ross JS, Figge H, Bui HX, del Rosario AD, Jennings TA, Rifkin MD, Fisher HA. Prediction of pathologic stage and postprostatectomy disease recurrence by DNA ploidy analysis of initial needle biopsy specimens of prostate cancer. Cancer. 1994;74(10):2811-2818.

10. Lerner SE, Blute ML, Bergstralh EJ, Bostwick DG, Eickholt JT, Zincke H. Analysis of risk factors for progression in patients with pathologically confined prostate cancers after radical retropubic prostatectomy. J Urol. 1996;156(1):137-143.

11. Carmichael MJ, Veltri RW, Partin AW, Miller MC, Walsh PC, Epstein JI. Deoxyribonucleic acid ploidy analysis as a predictor of recurrence following radical prostatectomy for stage T2 disease. J Urol. 1995;153(3 Pt 2):10151019.

12. Coetzee LJ, Layfield LJ, Hars V, Paulson DF. Proliferative index determination in prostatic carcinoma tissue: is there any additional prognostic value greater than that of Gleason score, ploidy and pathological stage? J Urol. 1997; 157(1):214-218.

13. So MJ, Cheville JC, Katzmann JA, Riehle DL, Lohse CM, 
Pankratz VS, Sebo TJ. Factors that influence the measurement of prostate cancer DNA ploidy and proliferation in paraffin embedded tissue evaluated by flow cytometry. Mod Pathol. 2001;14(9):906-912.

14. Bocking A, Tils M, Schramm M, et al. DNA-cytometric grading of prostate cancer systematic review with descriptive data analysis. Pathol Discov. 2014;2:7.

15. Ward JF, Slezak JM, Blute ML, Bergstralh EJ, Zincke H. Radical prostatectomy for clinically advanced (cT3) prostate cancer since the advent of prostate-specific antigen testing: 15-year outcome. BJU Int. 2005;95(6):751-756.
16. Clinical practice guidelines for the use of tumor markers in breast and colorectal cancer. Adopted on May 17, 1996 by the American Society of Clinical Oncology. J Clin Oncol. 1996;14(10):2843-2877.

17. Mora LB, Moscinski LC, Diaz JI, Blair P, Cantor AB, Pow-Sang JM. Stage B Prostate cancer: correlation of DNA ploidy analysis with histological and clinical parameters. Cancer Control. 1999;6(6):587-591.

18. Swanson GP, Quinn D. Using molecular markers to help predict who will fail after radical prostatectomy. Prostate Cancer. 2011;2011:290160. 